\title{
EFFICIENCY DEVELOPMENT IN THE GERMAN PHARMACEUTICAL MARKET
}

\author{
Tim Gaebert ${ }^{1}$, Michaela Staňková1 \\ ${ }^{1}$ Department of Statistics and Operation Analysis, Faculty of Business and Economics, Mendel University in Brno, \\ Zemědělská 1, 61300 Brno, Czech Republic
}

Link to this article: https://doi.org/10.11118/actaun202068050877

Received: 25. 7. 2020, Accepted: 4. 9. 2020

To cite this article: GAEBERT TIM, STAŇKOVÁ MICHAELA. 2020. Efficiency Development in the German Pharmaceutical Market. Acta Universitatis Agriculturae et Silviculturae Mendelianae Brunensis, 68(5): 877-884.

\begin{abstract}
Changes in Germany legislation since 2009 significantly limited the operation of German pharmacies. Since then, there has been a steady decline in the total number of pharmacies. This article deals with the efficiency change within the German retail and wholesale pharmaceutical sectors in the years 2009 to 2016. The efficiency calculation was based on the nonparametric data envelopment analysis method and the Malmquist index was used to evaluate changes. Two components of Malmquist index were also monitored separately, capturing changes in the area of technical efficiency and changes in the area of the production possibility set. The results point to the increasing efficiency which means that decreasing number of pharmacies is caused by concentration tendencies rather than by negative effects of government decisions.
\end{abstract}

Keywords: efficiency, data envelopment analysis, Germany, Malmquist index, pharmacy

\section{INTRODUCTION}

The starting point of the present study is the ongoing pharmacy death in Germany since 2009. This year started major legislative changes in the pharmaceutical sector. In particular, for reasons of consumer protection and in order to safe and high quality medical service, changes within the ownership of pharmacies have been introduced. The European Court of Justice upheld the German ban on outside ownership of pharmacy shops, ensuring that only qualified pharmacists are allowed to run pharmacy shops, and pharmacy chains will remain banned. Among other things, this legislation stipulates that in Germany pharmacist is only allowed to own up to four separate establishments. Until then, the otherwise lucrative German pharmaceutical market has thus become a very risky for some entities (for example pharmaceutical dealers Doc Morris and Celesio).

The European Court of Justice (2016) ruling of October 19, 2016 tipped the price fixing for prescription medicines for foreign mail order pharmacies in the
European Union. So far, the prices of prescription medicines in Germany have been regulated by the state; only for over-the-counter medicines is there a free fixed price. From the point of view of the German pharmacists' associations, the judgment of the European Court of Justice gave foreign shipping providers an unexpected competitive advantage. While German (mail order) pharmacies are bound to fixed prices for prescription medicines, foreign online pharmacies can grant discounts. German customers can submit their doctor's prescription within the European Union and receive bonuses - not in Germany. This could be a reason for the ongoing pharmacy decline in Germany.

In his analysis of EU and constitutional law, Dettling (2018) states that to ensure the high-quality, comprehensive supply of medicines to patients, flexible shipping ban - i.e. a shipping ban to private end users for prescription drugs, where exceptions to the ban are for example doctors, hospitals and healthcare facilities - as the best alternative must be introduced. With the judgment of the highest 
judges, the course was set for a growing online trend for prescription drugs, what leads to the situation, where pharmacies are uncertain about the future and fear for their existence. According Evans (2017) the sales of foreign mail-order pharmacies continue to increase, while nationally-based pharmacies have to close further - the reasons have not yet been defined. For example, the Deutschen Apotheker Zeitung reports on faster falling pharmacy numbers in Germany in 2018, which shows a realistic development (Müller-Bohn, 2018).

To strengthen local pharmacies in Germany economically, a political consequence is the enforcement of a national shipping ban for prescription drugs - whether this alone can prevent pharmacy mortality in Germany is questionable. The reasons for the ongoing pharmacy death in Germany have not yet been investigated and can be complex. The decreasing number of retail pharmacies can be justified, for example, with the rising wage costs of employees, with a non-adjusted prescription payment or with the growing online competition, and a combination of several reasons is also conceivable. Therefore, the efficiency of pharmacies in Germany should first be described in order to derive reasons for pharmacy death. If only inefficient pharmacies disappeared from the market, it would be a natural competitive process in the long run. This may be a natural effect of globalization, where more efficient foreign pharmacies are gradually crowding out less efficient German competitors. However, if efficient pharmacies went out from the market, this would be a significant problem, which may have a basis, for example, in political decisions.

Generally, two different approaches can be used to measure efficiency - the parametric and the nonparametric approach. Parametric methods rely on statistical techniques to estimate the parameters of specific function. Typically, parameters of production or cost function are estimated like in Staňková and Hampel (2019a). Parametric approach is criticized for the assumption that the production or cost function has the same functional form for all the companies. In addition, econometric estimation of efficiency can produce inconsistent parameter estimates. Non-parametric methods compare the observed inputs and outputs of each firm with that of the most performing firms in the information dataset without having information about the production function. Based on Hollingsworth (2003), Odeck and Brathen (2012) or Lampe and Hilgers (2015) it can be argued that method of data envelopment analysis (DEA) is the most common method for efficiency evaluation. Recent studies using nonparametric methods to evaluate the efficiency are, for example, Staňková and Hampel (2018) or Staňková and Hampel (2019b). This method is criticized not only because of its deterministic nature, but also because of its high sensitivity to omitting essential variables.
The DEA method allows to track the development of efficiency over time. For example, the Malmquist index (MI) can be used for this purpose. It is possible to directly analyse the values of MI or perform the decomposition of MI into two basic components and thus analyse separately the change in technical efficiency and the change in the production possibility frontier. In the field of a pharmaceutical industry, the DEA method (including the MI calculation) was used in the Al-Refaie et al. (2015). In this paper, they focused on analysing Jordanian pharmaceutical company and its packaging lines in the penicillin cell over the period of seven months (April 2010 to October 2010). Number of bottles and the actual number of man working hours were selected as input variables. Whereas, the actual number of output bottles was assumed as the sole output. Their results show that there is still room for improvement. However, they have also proved that at least in this particular case, a positive total factor productivity change is present.

However, DEA (along with the MI) is a popular tool in other sectors as well. $\mathrm{Hu}$ and Liu (2015), based on data from Australian construction companies from 2000 to 2010, examined the efficiency of carbon reduction. Therefore, the output variable was the amount of emissions and added value. The input variables were the number of employees, the amount of work done, and the value of energy consumption. Their results show that, given government interventions and also by companies themselves, carbon emissions in the construction sector are indeed effectively reduced.

Amani, Valami and Ebrahimnejad (2018) used MI and DEA in power industry of Iran. On the data of 16 regional electricity companies from 2013 and 2014, they examined the changes in efficiency and in the efficiency frontier. Their results show that the efficiency ratio was stable over the two consecutive years.

Walheer (2019) investigate the causes of the performance changes by MI. He studied the performances of US electricity plants over the period 2000-2012. His results suggest that combining renewable and non-renewable electricity generations within a plant do not improves the performance of the plants. Other current studies using the DEA method and MI are for example Yan (2019), Fernández et al. (2018) and Sheng et al. (2015).

The main aim of this article is to assess the development of efficiency within the pharmaceutical industry in Germany in 2009-2016, what should help to clarify the situation in the pharmaceutical market facing a problem of the declining number of pharmacies. For this purpose a non-parametric DEA method (together with MI) is chosen. To achieve robust results, the MI will be estimated using several DEA models based on different settings. 


\section{MATERIALS AND METHODS}

Financial (annual accounting) data on companies from the years 2009 to 2016 are obtained from the Orbis database. Based on the NACE classification, the pharmaceutical industry can be found in two groups. The first group consists of 'Wholesale of pharmaceutical goods' (code 4646) falling into the wholesale category, the second group consisting of 'Dispensing chemist in specialized stores' (code 4773) falling into the retail category.

It was found that entities belonging to the retail category rarely made their financial statements available. From this group of companies, only variable operating revenue (turnover) and number of employees could be traced in the required quantity. For the whole period under review, these are data from 2751 companies. Within the wholesale sector, a smaller number of companies are registered than in retail. In terms of the number of entities, the retail sector is more than twice as large as the wholesale sector. However, most of the companies in retail sector are so-called sole traders (eingetragener Kaufmann). In contrast, other types of companies predominate in wholesale. Typically, this is a limited partnership with a limited liability company as a general partner (GmbH \& Co KG) or a Limited liability company $(\mathrm{GmbH})$. Generally, these types of companies have more accessible financial information compared to sole traders.

Within the wholesale sector it is therefore possible to use other variables in addition to the above mentioned operating revenue (turnover) and number of employees. The DEA method requires that variables have a strong link to the production process. As the input variables we choose capital, number of employees and total assets. Operating revenue (turnover) and added value represents the output variables. In order to obtain as many companies as possible we will deal with unbalanced data set. Due to selected variables it was possible to work with data from 6866 companies for the whole monitored period. Given the fact that data from thousands of companies was available in retail and wholesale sector, this sample can be considered representative.

With regards to the aim, the DEA method was chosen. This method makes it possible to compare the efficiency of individual companies (so-called DMUs). MI is used to compare the development of efficiency over time. The MI makes it possible to distinguish between a change in technical efficiency and a change in the efficiency frontier (production frontier).

To get robust results of efficiency, we decided to estimate six DEA models with different settings. More specifically, we provide the MI estimate within the six different DEA models. Since we assume that in the case of ineffective DMUs it will not be appropriate to consider the correction in the same amount in all variables, non-rational models were selected. These non-radial (or so-called slack-based) models consider possible slacks in one or more variables. In these models, different assumptions were also made regarding the returns to scale and orientation of the model. Technical details about these models can be found in Cooper, Seiford and Tone (2007). An overview of used DEA models including their settings is shown in Tab. I.

All the procedures described above are performed in the MATLAB R2019b computing system and DEA SolverPro (version 15).

\section{RESULTS AND DISCUSSION}

The complex reasons for pharmacy deaths in Germany have not yet been investigated, so no instruments to counter pharmacy closures have been identified. Data or current jurisprudence as well as changes in the law that could justify a pharmacy mortality and could be attributed to an exact period of time are up to the lifting of the price fixing for European online senders by the judgment of the European Court of Justice of October 19, 2016 (European Court of Justice, 2016), not known.

In the analysis to date, however, trends and market research data have been collected. On the one hand, Fig. 1 shows a trend towards branching out of pharmacies despite a decreasing total number of pharmacies. In 2010 there were 15,277 individual pharmacies and 2,686 pharmacies in Germany with at least one branch. In 2015 there were only 12,851 individual pharmacies and 3,117 pharmacies with at least one branch pharmacy (ABDA, 2019). According to German law, a pharmacy owner can operate up to three branch pharmacies in addition to a main

I: Overview of employed DEA models and their settings

\begin{tabular}{|c|c|c|}
\hline Name & Orientation & Returns to scale \\
\hline Model 1 & Non-oriented & Constant \\
\hline Model 2 & Non-oriented & Variable \\
\hline Model 3 & Input & Constant \\
\hline Model 4 & Input & Variable \\
\hline Model 5 & Output & Constant \\
\hline Model 6 & Output & Variable \\
\hline
\end{tabular}




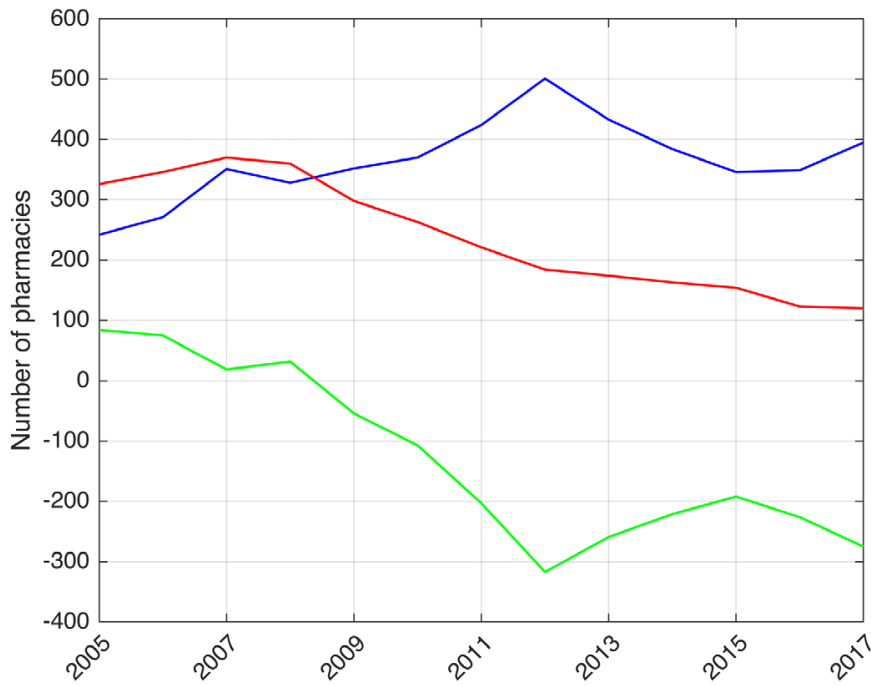

1: Development number of new opening pharmacies (red), closed (blue) and change (increase or decrease) in the number of pharmacies in Germany for the period 2005-2017 (ABDA, 2019)
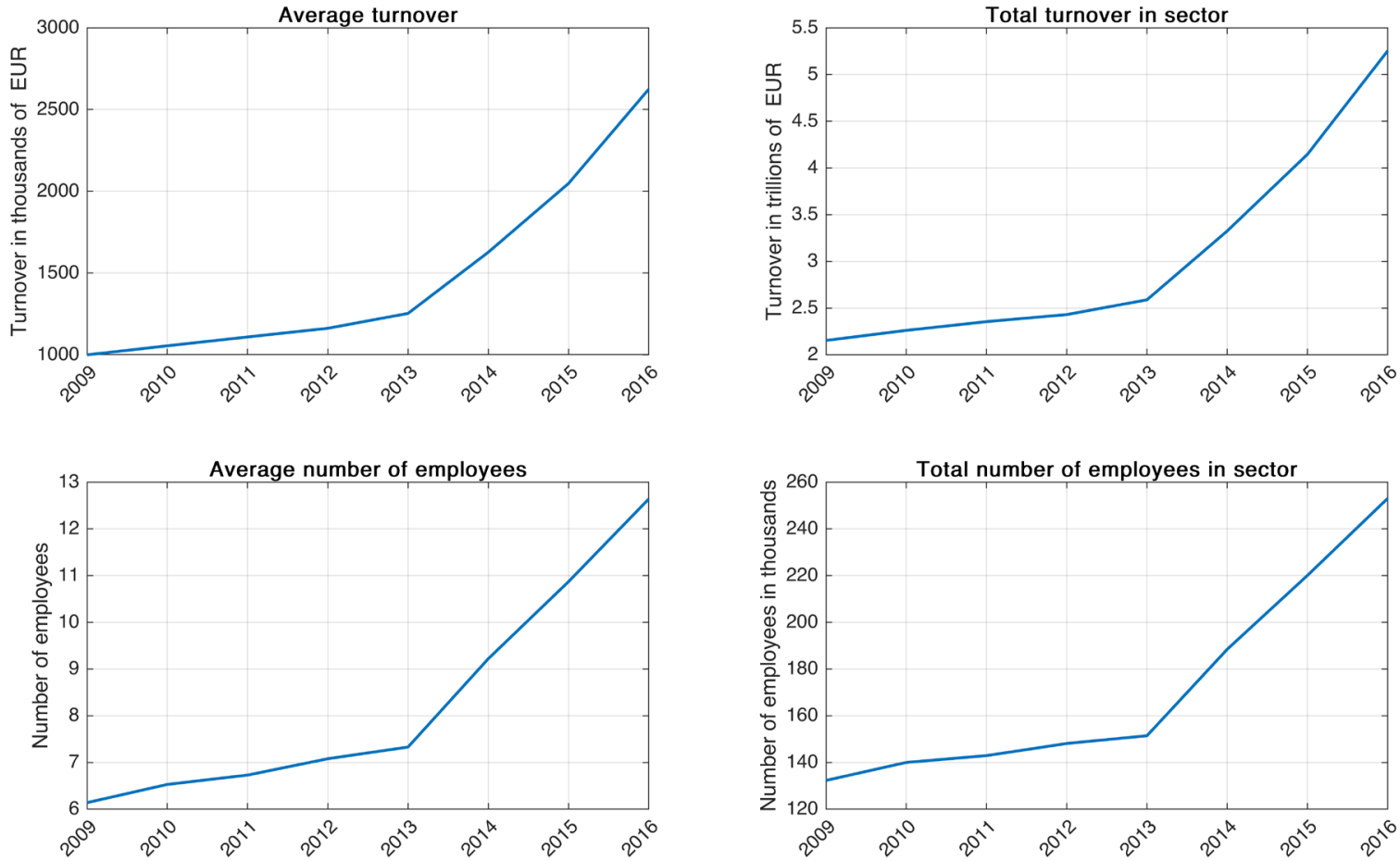

2: Average amount of operating revenue and average number of employees (left graphs) and estimated total turnover and total number of employees in the retail pharmacy sector (right graphs)

pharmacy. As a result, the trend of single pharmacies is declining, according to the current data view; they are increasingly affected by the closings.

Furthermore, the analysis shows that the year 2012 was particularly hard hit by pharmacy closures. The upper part of Fig. 1 shows the developments in pharmacy closings and new startups depending on the years. In the lower area of Fig. 1, the new openings of the pharmacies are compared to the closings. In the years 2005 to 2008 there are positive values, which mean more new pharmacies than closings. As of 2009, only negative values that represent pharmacy mortality are due to the greater number of closings than new openings. The most negative value (-317 pharmacies) can be assigned to 2012. The reasons for this are not known.

Fig. 2 shows the development of amount of operating revenue (turnover) and number of employees in individual years in the retail sector. In the left graphs, there are the average amount of operating revenue and number of employees 
II: Development of Herfindahl-Hirschman index for retail pharmacies sector

\begin{tabular}{lllllllll}
\hline Year & 2009 & 2010 & 2011 & 2012 & 2013 & 2014 & 2015 & 2016 \\
\hline HHI & 0.005 & 0.005 & 0.006 & 0.006 & 0.008 & 0.021 & 0.021 & 0.033 \\
\hline
\end{tabular}
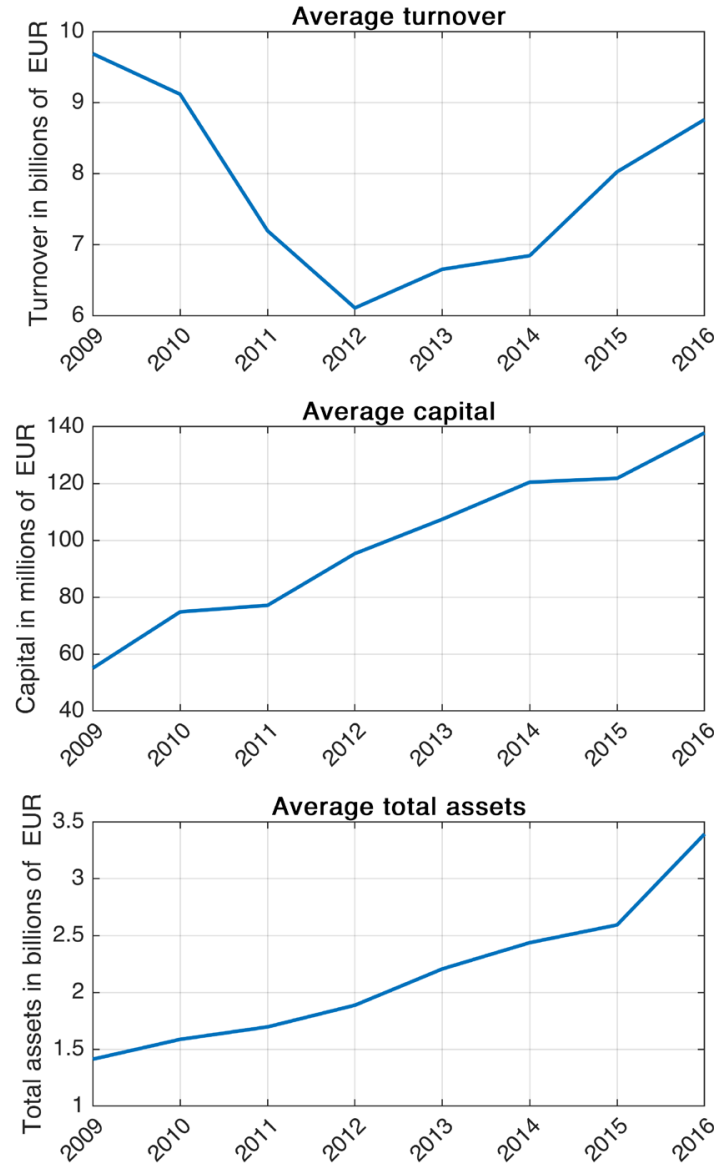

3: Key characteristics development in the wholesale pharmacy sector

in individual years. In the right graphs, the total characteristics of the sector for given year are calculated using known number of pharmacies multiplied by mean value estimation given by sample taken from the Orbis database.

It can be stated, that the output represented by turnover is constantly increasing. Development of the number of employees has is analogous to turnover. Given the constant decline in the number of pharmacies during the reporting period, it can be stated that active companies are improving their situation. Estimated total number of employees as well as estimated total turnover of the retail pharmacy sector increased visibly. From this perspective the retail pharmacy sector seems to be efficient, because a larger volume of sales is redistributed to a smaller number of pharmacies. Given that the average pharmacy is also growing in number of employees, it can be assumed that these companies are expanding their business and serving customers that had been taken over from less efficient competitors.
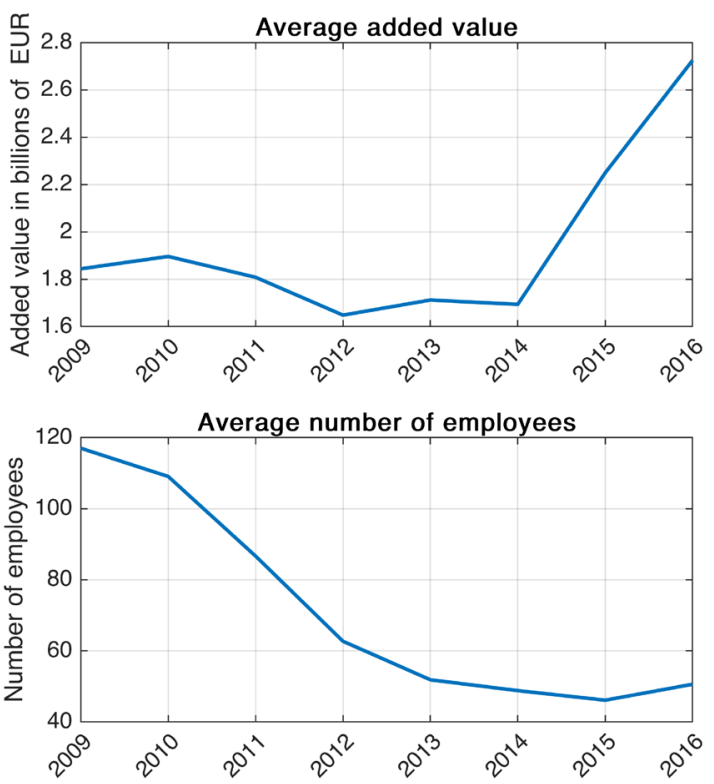

This assumption can be supported by assessment of concentration in retail pharmacies sector. We use Herfindahl-Hirschman index (HHI), see Whinston (2006), based on turnover for this purpose. In Tab. II, there is visible increasing value of $\mathrm{HHI}$ which means higher degree of concentration. Moreover, from 2013 to 2014 we can see substantial change, which corresponds to the structural break in turnover and number of the employees visible in Fig. 2.

Within the wholesale sector it was possible to work with more variables, see Fig. 3. However, when looking at the development in terms of turnover and number of employees, it can be stated that in this part of the sector the development of selected variables differs from the retail sector. In terms of turnover, there is a noticeable decrease until 2012 and subsequent growth. In the case of the number of employees, the average number of employees is falling until 2015. On the contrary, the average capital and thus the average amount of assets have been growing throughout the period. In contrast to 
III: Number of companies entering the calculation of efficiency in individual years

\begin{tabular}{ccccccccc}
\hline Year & $2009-2010$ & $2010-2011$ & $2011-2012$ & $2012-2013$ & $2013-2014$ & $2014-2015$ & $2015-2016$ \\
\hline Companies & 182 & 188 & 212 & 251 & 226 & 224 & 175 \\
\hline
\end{tabular}
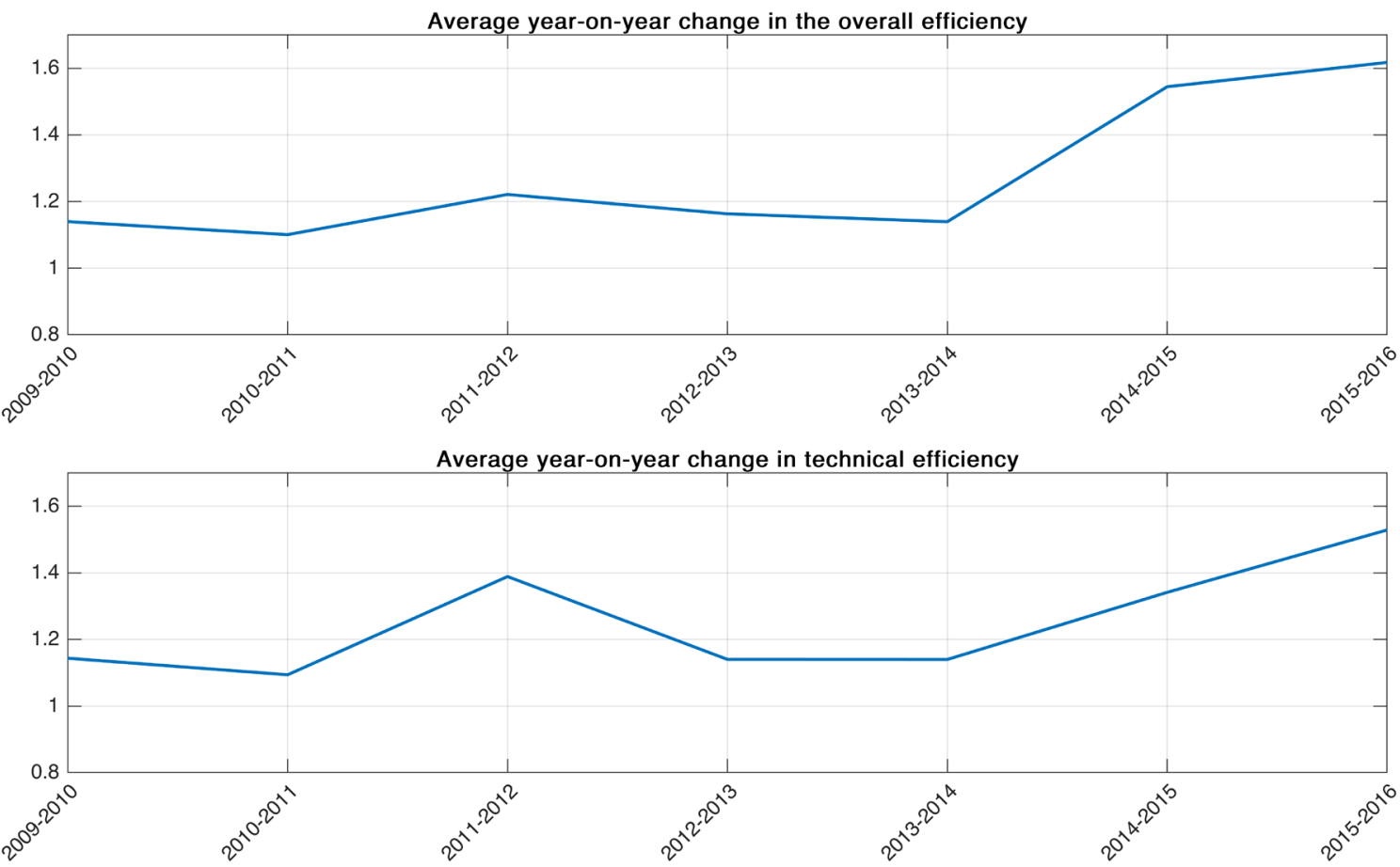

Average year-on-year change in production possibility frontier

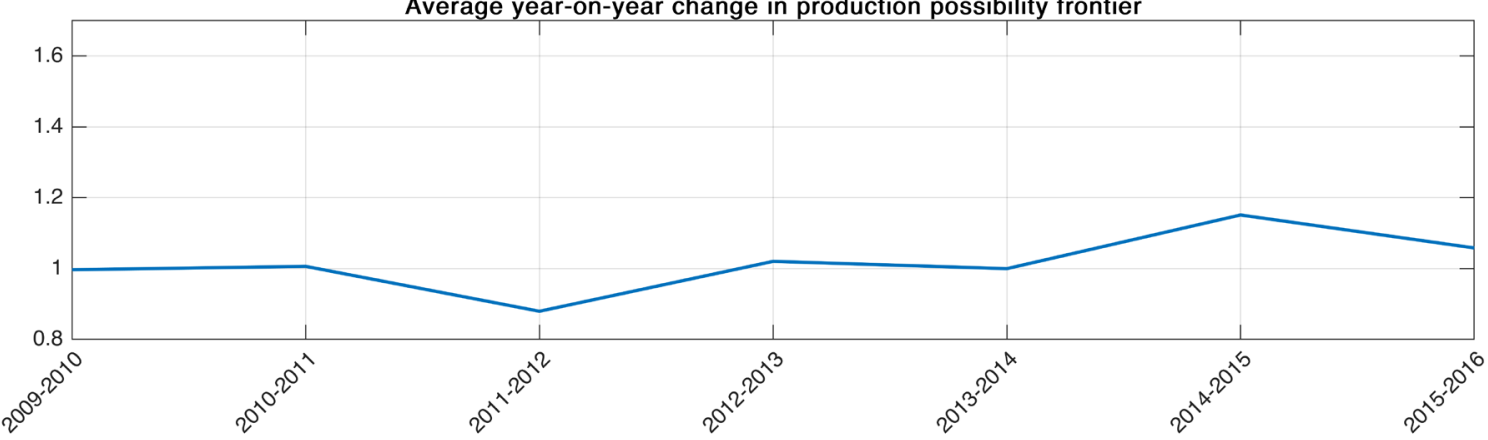

4: Average year-on-year values of MI and its components in individual periods

this finding, there is a greater mechanization of this sector, as employees are being replaced by other production factors (typically machines).

Due to the availability of data within wholesale sector, it is possible to look more closely at the evaluation of efficiency than by calculating the average pharmacy values. To calculate the change in efficiency over time (i.e. calculate the MI), it is essential that the DMU (pharmacy) has available data in all variables for both periods examined. To meet this prerequisite, a subset of companies has been selected; see Tab. III, where number of companies presented in both neighbouring years is presented. Although the number of DMU varies from year to year depending on the availability of the data, the results of these calculations can be considered representative, as 99 DMUs appeared in all monitored periods. And more, always at least one company is marked as fully efficient throughout the reporting period in each model. Therefore, it can be stated that although the number of DMUs varies from period to period, the average efficiency values will be sufficiently representative for the whole industry.

Fig. 4 shows the development of efficiency (in average of values given by all the six models from Tab. I) in the wholesale sector for resulting values of MI and its two parts: frontier shift and catch-up effect (technical efficiency change). In all periods, MI is a number greater than one - so in can be stated, that the situation on the wholesale sector is improving every year. If we analyse the 
development within the partial components of MI, then in the case of technical efficiency it can be stated that it is always a value greater than one. That means that in average technical efficiency increased. In Fig. 4 there can be seen a jump in efficiency growth in this sector from 2011 to 2012. In the next two periods, the increase in efficiency is at a similar level as in 2010-2011 and after 2014 there is a linear increase in efficiency. In most periods, the frontier shift value is greater than 1. In that period efficiency frontier (production frontier) increased. Only in the period 2011-2012 there was a slight decrease in the efficiency frontier. Given that for the period 2011-2012 the MI is greater than one, it can be stated that the increase in technical efficiency is greater (stronger) than the decrease within the production possibility set.
However, such conflicting fluctuations in MI components around 2012 can be clearly interlinked. In 2012, the German economy (similarly to the neighbouring Czech Republic economy, for example) experienced some economic downturn. According to data from The World Bank Group, GDP fell from 3.758 trillion US\$ in 2011 to just 3.544 trillion US\$ in 2012 (this is the first decline after the 2009 crisis). The problems arising directly in the pharmaceutical sector are also confirmed by the ABDA report (2019). According to ABDA (2019), a drop in sales from prescription reimbursement can be seen especially in 2011 and 2012. All these facts then explain the decline in production possibility frontier in 2011-2012. Nevertheless, in the same period there was a large increase in efficiency; this catch-up effect can be partially caused by the frontier decline.

\section{CONCLUSION}

Although the number of pharmacies in Germany is declining, the industry as a whole is doing well in terms of its operations. In the case of the retail sector, due to the availability of data, the situation is not yet fully clarified. However, it can be assumed that there is some improvement here as well. Average turnover as well as total turnover of the sector are growing over time and have almost the same development. Both average and total number of employees have an increasing tendency too. It can be assumed that still active pharmacies take over not only orders, but also employees from their competitors. This finding could calm down entities such as the government, as a decline in the number of pharmacies in retail should not lead to major unemployment problems.

The wholesale pharmaceutical sector shows slightly different development. The average number of employees is declining here. Conversely, the average amount of capital and assets is growing. It can be assumed that automatization and robotisation enhanced by online sales is observed in the pharmaceutical industry. In the case of wholesale sector, an increase in efficiency and the production possibility frontier was demonstrated. This positive development was only briefly and slightly disrupted by the economic situation in 2012.

Finally, although the number of pharmacies in Germany is declining, in terms of the overall situation on this market, the functioning of active pharmacies is improving at least in term of efficiency. Nevertheless, there are still open question related for example to different development in retail and wholesale pharmacy sectors, where selling abroad may be important factor. In the future work, attention to international relations will be explored.

\section{Acknowledgements}

This article was supported by the grant No. PEF/TP/2020002 of the Internal Grant Agency PEF MENDELU.

\section{REFERENCES}

BUNDESVEREINIGUNG DEUTSCHER APOTHEKERVERBÄNDE (ABDA). 2019. Die Apotheke: Zahlen Daten - Fakten, 2019. ABDA.

AL-REFAIE, A., NAJDAWI, R., AL-TAHAT, M. D. and BATA, N. 2015. Window Analysis and Malmquist Index for Assessing Efficiency in a Pharmaceutical Industry. In: World Congress on Engineering WCE 2015. July 1-3, London. Vol. 1, pp. 132-136.

AMANI, N., VALAMI, H. B. and EBRAHIMNEJAD, A. 2018. Application of Malmquist productivity index with carry-overs in power industry. Alexandria Engineering Journal, 57(4): 3151-3165.

COOPER, W. W., SEIFORD, L. M. and TONE, K. 2007. Data envelopment analysis: A comprehensive text with models, applications, references and DEA-solver software. $2^{\text {nd }}$ Edition. New York: Springer Science \& Business Media. 
DETTLING, H.-U. 2018. Arzneimittelversorgung und flexibles Versandverbot für verschreibungspflichtige Arzneimittel: Eine unions-und verfassungsrechtliche Analyse. $1^{\text {st }}$ Edition. Eschborn: Govi.

EUROPEAN COURT OF JUSTICE. 2016. Deutsche Parkinson Vereinigung e.V., C-148/15. Judgment of the Court of 19 October 2016. European Court of Justice.

EVANS, J. 2017. Versandhandelsumsatz: Doc Morris legt zu. Pharmazeutische Zeitung. [Online]. Available at: https://www.pharmazeutische-zeitung.de/ausgabe-062017/doc-morris-legt-zu [Accessed: 2020, August 15].

FERNÁNDEZ, D., POZO, C., FOLGADO, R., JIMÉNEZ, L. and GONZALO, G.-G. 2018. Productivity and energy efficiency assessment of existing industrial gases facilities via data envelopment analysis and the Malmquist index. Applied Energy, 212: 1563-1577.

HOLLINGSWORTH, B. 2003. Non-Parametric and Parametric Applications Measuring Efficiency in Health Care. Health Care Management Science, 6(4): 203-218.

HU, X. and LIU, C. 2015. Managing undesirable outputs in the Australian construction industry using Data Envelopment Analysis models. Journal of Cleaner Production, 101: 148-157.

LAMPE, H. W. and HILGERS, D. 2015. Trajectories of efficiency measurement: A bibliometric analysis of DEA and SFA. European Journal of Operational Research, 240(1): 1-21.

MÜLLER-BOHN, T. 2018. 157 weniger - Apothekenzahl sinkt immer schneller. DAZ.online. [Online]. Available at: https://www.deutsche-apotheker-zeitung.de/news/artikel/2018/09/10/157-wenigerapothekenzahl-sinkt-immer-schneller [Accessed: 2020, August 15].

ODECK, J. and BRATHEN, S. 2012. A meta-analysis of DEA and SFA studies of the technical efficiency of seaports: A comparison of fixed and random-effects regression models. Transportation Research Part A: Policy and Practice, 46(10): 1574-1585.

SHENG, Y., WU, Y., SHI, X. and ZHANG, D. 2015. Energy trade efficiency and its determinants: A Malmquist index approach. Energy Economics, 50(C): 306-314.

STAŇKOVÁ, M. and HAMPEL, D. 2018. Efficiency Comparison in the Development of Building Projects Sector. In: Mathematical Methods in Economics 2018: Conference Proceedings. Praha: MatfyzPress: pp. 503-508.

STAŇKOVÁ, M. and HAMPEL, D. 2019a. Efficiency of the Building Project Sector in the Czech Republic - Stochastic Frontier Analysis Approach. In: International Conference of Numerical Analysis and Applied Mathematics (ICNAAM 2018). Melville: American Institute of Physics (AIP), 2116(1): 400007.

STAŇKOVÁ, M. and HAMPEL, D. 2019b. Bankruptcy Prediction Based on Data Envelopment Analysis. In: Mathematical Methods in Economics 2019: Conference Proceedings. České Budějovice: Jihočeská univerzita v Českých Budějovicích, pp. 31-36.

WALHEER, B. 2019. Malmquist productivity index for multi-output producers: An application to electricity generation plants. Socio-Economic Planning Sciences, 65(C): 76-88.

WHINSTON, M. D. 2006. Lectures on Antitrust Economics. Cambridge: The MIT Press.

YAN, J. 2019. Spatiotemporal analysis for investment efficiency of China's rural water conservancy based on DEA model and Malmquist productivity index model. Sustainable Computing: Informatics and Systems, 21: 56-71.

Contact information

Michaela Staňková: michaela.stankova@mendelu.cz 